PN4-2

\section{Medical Response against Terrorism: Training and Education}

Henry J. Siegelson, MD, FACEP

Atlanta, Georgia USA

Terrorism represents a profound threat to our communities. Terrorists, whether representing foreign governments, religious fervor, or individual anger, have the capacity to harm our cities with explosives and weapons of mass destruction.

The explosions at the World Trade Center in New York City, the Murrah Building in Oklahoma City, and Centennial Park in Atlanta dramatize the susceptibility of communities in the USA to a terrorist attack. The Sarin nerve gas attack in Japan, the stockpiling of chemical and biological weapons by Iraq, and the problems of controlling access to the former Soviet Union's highly radioactive military stores present special challenges to the medical community.

While fire, Hazardous Materials (HazMat), emergency medical services (EMS), law enforcement, and federal and military agencies prepare to meet the threat of a terrorist attack, all victims eventually will seek care from the local hospital. Hospitals represent an invaluable community, regional, and state resource, and are an essential component of society's response to natural and man-made disasters.

Hospitals provide the majority of medical care to victims after a disaster. It is imperative that hospitals develop the capacity to safely provide assistance to the affected community after a terrorist attack.

In most training programs for nurses and physicians worldwide, very little or any effort currently is extended to prepare graduates to recognize and respond to the demands of victims of a terrorist attack. Globally, there are few hospitals with the capacity to safely assess, decontaminate, and treat victims of a terrorist attack.

A broad range of training and educational programs must be developed to improve the ability of the nurses, physicians, and hospitals to meet this demand. This training will enable nursing schools, medical schools, and other areas of higher learning to train students in the medical consequences of a terrorist attack. Postgraduate training should be extended to all communities to share this important material. This training must necessarily focus on Weapons of Mass Destruction: explosives, chemical weapons, biologic weapons, radioactive materials, and nuclear weapons.

In the United States, a range of public and private efforts developed training for the medical sector. Virtually every community currently is assessing its capability to respond to a terrorist attack. Planning must take place at local, regional, and federal levels. Central coordination by federal agencies will speed the development and availability of this information. Federal and local officials must agree upon minimum standards of preparedness for the cities as well as the nation.

While every effort must be made to prepare the medical community, it is essential that this preparation not take place in a vacuum. All responding agencies must develop plans that will meet the needs of the community in times of crisis. This planning must be multijurisdictional to include fire, EMS, HazMat, law enforcement, military, and medical systems. These responders must learn to respond in a coordinated fashion utilizing plans that have been tested, exercised, and generally accepted.

Policies and procedures must be developed to prepare hospitals to deal with the medical consequences of a terrorist attack. Decontamination systems appropriate for the medical facilities and their communities also must be developed.

Tabletop exercises and realistic drills that involve community response agencies will: 1) Coordinate the community response to a mass casualty event; 2) Highlight deficiencies; 3) Develop lasting relationships between fire, EMS, emergency management, and hospitals; and 4) Enable a safe response to a vast range of hazards

Summary: Hospitals are a valuable disaster resource. Internal systems must be developed that will enable hospitals to offer a safe response to a terrorist attack. Every hospital must have the capacity to safely assess and treat at least one patient exposed to a hazardous material.

\section{References}

1. Siegelson HJ: Legacy of the 1996 Olympic Games: LEPC experience with fire, EMS, and hospital preparedness. Local Emergency Planning Committee Newsletter. February-March, 1997.

2. Auf der Heide EA: Disaster planning, Part II: Disaster problems, issues, and challenges identified in the research literature. Emergency Medicine Clinics of North America. 1996;14:453-481.

3. "Okumura T, et al: Report of 640 Victims of the Tokyo subway sarin attack. Annals of Emergency Medicine,1996; : 129-135.

4. Nozaki $\mathrm{H}$, et al: Secondary exposure of medical staff to sarin vapor in the emergency room. Intensive Care Medicine 1995;21:1032-1035.

5. Levitin $\mathrm{H}$, Siegelson $\mathrm{H}$ : Hazardous materials: Medical disaster planning and response. Emergency Medicine Clinics of North America. 1996;14: 327-348.

6. Centers for Disease Control and Prevention: Recommendations for civilian communities living near chemical weapon depots: Guidelines for medical preparedness. Federal Register 1995;60:3308-3312.

7. Siegelson HJ: Chemical and biological weapons. Local planning: The medical perspective. The National Coordinating Council on Emergency Management Bulletin June 1997.

hsiegel@emory.edu

Keywords: capacity building; coordination; disasters; education; hazards; hospitals; mass casualties; planning; preparedness; terrorism; weapons

\section{PN4-3}

Medical Response to Biological Terrorism

Jeffrey L. Arnold, $M D$

The Ruth and Harry Roman Department of Emergency Medicine, Burns and Allen Research Institute, CedarsSinai Medical Center, Los Angeles, California USA

Perhaps the most frightening specter of our time is the possibility that terrorists or rogue nations might use biological warfare (BW) agents as weapons of mass 
destruction against civilian populations. With an increasing number of mass casualty incidents caused by terrorists in recent years, the threat of biological terrorism never has been more credible.

Most experts believe that the organisms or toxins most likely to be utilized by terrorists include anthrax, plague, Q-fever, tularemia, smallpox, viral encephalatides, viral hemorrhagic fevers, botulinum toxin, staphylococcal enterotoxin $\mathrm{B}$, and ricin toxin. BW agents share several characteristics that make them ideal tools in the hands of terrorists: 1) ease and low cost of production; 2) ease of dissemination as aerosols; 3 ) efficient exposure of great numbers of people through inhalation; 4) delayed effect; 5) high potency; 6) high subsequent mortality and morbidity; and 7) their ability to wreak psychological havoc. The unleashing of BW agents against a civilian population promises to be the ultimate medical disaster with the capability of completely overwhelming any health care system.

The challenge of BW agents only can be met if the emergency care system and individual emergency care providers are adequately prepared to respond to various bioterrrorist scenarios including threatened, suspected, and confirmed exposures to BW agents. Since bioterrorist attacks are likely to occur without warning, public health officials and Emergency Physicians must be able to detect bioterrorist attacks from epidemiological clues. Since most victims of an unannounced attack will delay seeking medical care, clinicians must be able to presumptively diagnose the diseases caused by common BW agents based on clinical criteria alone.

Saving lives will depend largely on the appropriate provision of pre-exposure immunoprophylaxis, postexposure prophylaxis, and the treatment of actual disease by physicians. The emergency care system also must provide adequate decontamination of victims and protection of health care workers from exposure to BW agents. Since such an attack also is expected to inflict enormous psychological damage, the health care system also must provide psychological care for survivors as well as health care workers.

The current system of medical response to biological terrorism in the USA emphasizes the critical role of local emergency care systems in the initial period after an attack. Unfortunately, our current ability to respond to bioterrorism has many serious limitations, including a lack of sufficient biosensor technology and a lack of adequate immunoprotection of civilian populations. The adequacy and timely availability of most protective, supportive, and therapeutic modalities also are limited significantly, especially if mass casualties were to present simultaneously to the health care system. A number of [US]federal agencies (Federal Emergency Management Agency, Federal Bureau of Investigation, Department of Health and Human Services, and Department of Defence) are working to alleviate these shortcomings through further organization, education, and scientific research.

Keywords: agencies, federal; biosensors; bioterrorism; education; Emergency Medicine; immunoprotection; preparedness; prophylax- is; research; response; terrorism; warfare, biological

\section{PN4-5}

Non-Conventional Warfare: Health Policy at the National Level

Yechezkel Levi, MD; Asher Winder, MD; Boaz Tadmor, $M D$; Ronen Durst, $M D$; Arieh Eldad, $M D$

Israel Defense Forces, Medical Corps Headquarters, Israel

In Israel, the Medical Corps of the Israel Defense Forces (IDF) takes responsibility together with civilian authorities for preparing countermeasures for possible conventional or non-conventional civilian mass casualties. Unlike a conventional mass casualty incident, when preparing for a non-conventional event, one is faced with dilemmas and controversial issues that are not easily solved. How can one make a risk-benefit assessment, if the threat is not precisely defined? What is the right way to address the public on this issue? What are the justified financial costs of countermeasures, and what degree of readiness is needed for something that might never happen? In this presentation, we discuss our experience in processing the threat and our model of countermeasures.

Assessing and understanding the risk is the first step. It is based primarily on intelligence data. Then, we add the nature of the organisms and the disease they may cause. Environmental models that predict the possible distribution of the causative agent complete the first assessment.

The second step is having identification and detection systems. This is achieved by routinely educating the medical staff about the possible causative agents. Automated detectors are supplied to military units located in various locations across the State of Israel and to mobile units of the Ministry of Environmental Protection. A central laboratory is available, for definitive identification.

Biological agents, unlike chemical agents, can pose their effects after a few days. The Ministry of Health has created an active surveillance program that operates routinely, and detects changes in the day-to-day morbidity pattern. The Ministry of Health has stockpiles of drugs like antibiotics and vaccines, as well as other medical equipment.

The plan for appropriate prophylactic and therapeutic measures is not obvious. The solution must cover a diverse range of causative agents. In addition, it should be suited to treat every segment of the population including infants, the elderly, and pregnant women.

Keywords: biological agents; costs; countermeasures; detection; health policy; intelligence; mass casualties; military; models; multicasualty incident; stockpiles; surveillance; warfare

\section{PN4-6}

Prevention and Management of Chemical and Biological Casualties

Boaz Tadmor, MD; Nir Marcus, MD;

Shlomo Givoni, $M D$; Asher Winder, $M D$ 